\title{
Prevalence of left ventricular hypertrophy in Type I diabetic patients with diabetic nephropathy
}

\author{
A. Sato, L. Tarnow, H.-H. Parving \\ Steno Diabetes Center, Gentofte, Denmark
}

Summary The increased mortality of patients with diabetic nephropathy is mainly due to cardiovascular disease and end stage renal failure. Left ventricular hypertrophy is an independent risk factor for myocardial ischaemia and sudden death. The aim of our cross-sectional study was to evaluate left ventricular structure and function in Type I (insulin-dependent) diabetic patients with diabetic nephropathy. M-mode and Doppler echocardiography were done on 105 Type I diabetic patients with diabetic nephropathy [61 men, age (means \pm SD) $44 \pm 9$ years, and albuminuria [median(range)] 567(10-8188) $\mathrm{mg} / 24 \mathrm{~h}$, serum creatinine 109 (53-558) $\mu \mathrm{mol} / \mathrm{l}]$, and 140 Type I diabetic patients with persistent normoalbuminuria [79 men, $47 \pm 10$ years, urinary albumin excretion rate $8(0-30) \mathrm{mg} / 24 \mathrm{~h}$, and serum creatinine 81 (55-121) $\mu \mathrm{mol} / \mathrm{l}]$. Patients with and without nephropathy were comparable with respect to sex, body mass index, and duration of diabetes. Arterial blood pressure was slightly higher in patients with nephropathy: $140 / 79 \pm 17 / 9 \mathrm{~mm} \mathrm{Hg}$ vs $134 / 78 \pm 15 / 8 \mathrm{~mm} \mathrm{Hg}$, $p<0.01$, and the majority of proteinuric patients re-

Received: 16 April 1998 and in final revised form: 5 August 1998

Corresponding author: L. Tarnow, M.D., Steno Diabetes Center, Niels Steensens Vej 2, DK-2820 Gentofte, Denmark

Abbreviations: Type I diabetes, insulin-dependent diabetes; LVH, left ventricular hypertrophy; LVM, left ventricular mass; LVMI, left ventricular mass index; E/A ratio, between peak diastolic velocity (PE) and peak atrial velocity (PA); LVDD, left ventricular end-diastolic diameter; LVDS, left ventricular end-systolic diameter; STD, ventricular septum thickness; PWTD, posterior wall thickness in diastole; FS, fractional shortening; IVRT, isovolumic relaxation time. ceived antihypertensive drugs, 84 vs $17 \%$, respectively, $p<0.001$. Left ventricular mass index was increased in the nephropathic group (means $\pm \mathrm{SD}$ ) $100.6 \pm 23.9 \mathrm{~g} / \mathrm{m}^{2}$ compared with the normoalbuminuric group $91.4 \pm 21.9 \mathrm{~g} / \mathrm{m}^{2}, p=0.002$. Left ventricular hypertrophy was found more often in patients with nephropathy 23 (14-31)\% compared with patients with normoalbuminuria $9(5-14) \%, p<0.005$. Diastolic function, assessed by the ratio between the peak diastolic velocity and the peak atrial systolic velocity (E/A ratio) and isovolumic relaxation time, was reduced in patients with vs without nephropathy: $1.17 \pm 0.29$ vs $1.34 \pm 0.32$, and $81.7 \pm 16.5$ vs $74.6 \pm$ 14.5, $p<0.001$ and $p=0.002$, respectively. Systolic function was about the same and normal in both groups. Our study suggests that an increase in left ventricular mass index and a decrease in diastolic function occurs early in the course of diabetic nephropathy. [Diabetologia (1999) 42: 76-80]

Keywords Left ventricular hypertrophy, Type I diabetes, diabetic nephropathy.
The increased mortality of patients with diabetic nephropathy is mainly due to cardiovascular disease and end stage renal failure. The relative mortality from cardiovascular disease is on average increased 40-fold in Type I (insulin-dependent) diabetic patients with nephropathy compared with the general population [1]. Abnormalities in well established cardiovascular risk factors cannot fully account for these findings. Increased left ventricular mass possibly contributes to the increased cardiovascular risk since left ventricular hypertrophy is an ominous prognostic sign and an independent risk factor for sudden death, ventricular dysrhythmia, myocardial 
ischaemia, coronary heart disease, and heart failure [2].

The aim of our cross-sectional case control study was to evaluate left ventricular structure and function in Type I diabetic patients with and without diabetic nephropathy.

\section{Subjects, materials and methods}

Patients. During the year 1993, 198 Type I diabetic patients with diabetic nephropathy who had had their glomerular filtration rate measured during the same year were recruited from the out-patient clinic at Steno Diabetes Center [3,4]. Diabetic nephropathy was diagnosed based on the following criteria: persistent albuminuria greater than $300 \mathrm{mg} / 24 \mathrm{~h}$ in at least two of three consecutive $24 \mathrm{~h}$ urine collections, presence of retinopathy and no clinical or laboratory evidence of kidney or renal tract disease other than diabetic glomerulosclerosis, as described previously [5]. As control subjects we selected 190 patients with longstanding Type I diabetes and persistent normoalbuminuria. By the year 1997 sixteen patients had died and nine had emigrated, thus we invited the remaining 363 patients to participate in the present echocardiographic study. The invitation was accepted by 296 patients. In 18 patients echocardiographic examination could not be done due to technical difficulties, 19 patients had ischaemic or valvular cardiac disease while 14 patients had additional reasons for circulatory volume overload, i.e. end stage renal failure therapy or pregnancy. These 51 patients were younger $(41.8 \pm 10.2)$ years, $p<0.001$, but did not differ from the patients participating in this study with respect to sex, duration of diabetes or prevalance of hypertension. All of these patients were excluded from the study and 245 Type I diabetic patients remained. The study was approved by the local ethics committee and all patients gave fully informed consent.

Echocardiography. M-mode and pulsed Doppler echocardiography was carried out according to the recommendations of the American Society of Echocardiography [6] using a VingmedCFM725 equipped with a $3.25 \mathrm{MHz}$ transducer. M-mode was recorded guided by a two-dimensional image in the parasternal long axis.

The following M-mode variables were measured: left ventricular end-diastolic diameter (LVDD) and end-systolic diameter (LVDS), ventricular septum thickness (STD) and posterior wall thickness in diastole (PWTD). Left ventricular mass (LVM) was calculated according to the Penn formula: $1.04\left[(\text { STD + LVDD + PWTD })^{3}-(\text { LVDD })^{3}\right]-13.6$ [7]. Left ventricular mass index (LVMI) was calculated by dividing LVM by the body surface area. Left ventricular hypertrophy was considered present if LVMI was greater than $131 \mathrm{~g} / \mathrm{m}^{2}$ in men and $100 \mathrm{~g} / \mathrm{m}^{2}$ in women, respectively [8]. Systolic function was assessed by fractional shortening (FS) of the left ventricle calculated by using the following equation: [(LVDD - LVDS)/ LVDD] $\times 100$. Left ventricular wall motion was inspected in each of the 16 segments defined by the American Society of Echocardiography [6]. Diastolic function was assessed by standard Doppler echocardiography done in the apical four chamber view. Left ventricular in-flow signals were obtained in the pulse mode by placing the sample volume between the mitral leaflets and adjusting the position until the highest peaks of diastolic velocity were obtained. The peak early diastolic velocity $(\mathrm{PE})$, the peak atrial systolic velocity (PA), and E/A ratio were determined from transmitral flow velocity. The isovolu- mic relaxation time (IVRT) was measured from aortic valve closure to mitral valve opening. All measurements were averaged over five cycles. Echocardiography was done by one experienced investigator who was not aware of the clinical data. Intraobserver error was less than $5 \%$.

Clinical measurements. In the outpatient clinic arterial blood pressure was measured in sitting position after $10 \mathrm{~min}$ rest with a standard sphygmomanometre and an appropriately sized cuff. Diastolic blood pressure was recorded at the disappearance of the fifth phase of the Korotkoff sounds. The mean of all office recordings of blood pressures measured in each patient during the last 6 months before the study was used [median(range), $n=2$ (1-9)]. Hypertension was considered to be present when arterial blood pressure was persistently greater than $160 / 95 \mathrm{~mm} \mathrm{Hg}$ or when patients received blood pressure lowering drugs (WHO criteria). Low dose diuretics given for oedema exclusively were not considered as antihypertensive drugs. Retinopathy was assessed by fundus photography after pupillary dilatation and graded: nil, simplex or proliferative diabetic retinopathy. Autonomic neuropathy was assessed by beat-to-beat variation. R-R intervals were recorded during deep breathing and measured with a ruler. The beatto-beat variation in the individual respiratory cycle was calculated as the difference between maximal and minimal heart rate [9].

Laboratory measurements. Urinary albumin concentration was measured using an enzyme immunoassay method [10] and expressed as the median of all $24 \mathrm{~h}$ collections $[n=2(1-9)]$ obtained during 6 months before the echocardiographic examination. $\mathrm{HbA}_{1 \mathrm{c}}$ was measured by HPLC (Bio Rad DIAMAT, Richmond, Calif., USA) (normal range 4.3-6.2\%) and serum creatinine, haemoglobin, total cholesterol, HDL-cholesterol and triglyceride concentrations were measured by standard laboratory technique.

Statistical analysis. Normally distributed variables are given as means \pm SD. Urinary albumin excretion rate, serum creatinine, and triglyceride concentration were log transformed before statistical analysis because of their positively skewed distribution and given as medians (range). Comparisons between groups were done by an unpaired Student's $t$-test or analysis of variance (ANOVA). Frequencies are given as percentage and $95 \%$ confidence interval. Non-continuous variables were compared with a Chi-square test. A $p$-value (two-tailed) less than 0.05 was considered statistically significant.

Multiple linear regression analysis was carried out with stepwise backwards selection introducing all variables showing association with LVMI in the univariate analysis $(p<0.1)$ and sex. All calculations were made with commercially available programmes, (Statgraphics, STSC, Rockville, Md., USA).

\section{Results}

The group of patients with nephropathy and the normoalbuminuric group were comparable with respect to sex, BMI, and duration of diabetes, but patients in the normoalbuminuric group were on average 3 years older. Clinical and laboratory data of all patients are shown in Table 1 . Some patients $(n=33)$ with previously persistent macroalbuminuria had a urinary albumin excretion rate below $300 \mathrm{mg} / 24 \mathrm{~h}$ at the time of investigation due to ongoing antihypertensive 
Table 1. Clinical and laboratory characteristics of Type I diabetic patients with and without diabetic nephropathy

\begin{tabular}{|c|c|c|c|}
\hline & $\begin{array}{l}\text { Normo- } \\
\text { albuminuria } \\
(n=140)\end{array}$ & $\begin{array}{l}\text { Diabetic } \\
\text { nephropathy } \\
(n=105)\end{array}$ & $p$-value \\
\hline Sex (men/women) & $79 / 61$ & $61 / 44$ & NS \\
\hline Age (years) & $47 \pm 10$ & $44 \pm 9$ & 0.02 \\
\hline $\begin{array}{l}\text { Duration of diabetes } \\
\text { (years) }\end{array}$ & $27 \pm 9$ & $28 \pm 8$ & NS \\
\hline BMI $\left(\mathrm{kg} / \mathrm{m}^{2}\right)$ & $24 \pm 3$ & $24 \pm 3$ & NS \\
\hline $\mathrm{HbA}_{1 \mathrm{c}}(\%)$ & $8.4 \pm 0.9$ & $9.3 \pm 1.2$ & $<0.001$ \\
\hline $\begin{array}{l}\text { Systolic blood pressure } \\
(\mathrm{mm} \mathrm{Hg})\end{array}$ & $134 \pm 15$ & $140 \pm 17$ & $<0.01$ \\
\hline $\begin{array}{l}\text { Diastolic blood pressure } \\
(\mathrm{mm} \mathrm{Hg})\end{array}$ & $78 \pm 8$ & $79 \pm 9$ & NS \\
\hline $\begin{array}{l}\text { Prevalence of anti- } \\
\text { hypertensive treatment }{ }^{\mathrm{a}}\end{array}$ & $17(11-23)$ & $84(77-91)$ & $<0.001$ \\
\hline $\begin{array}{l}\text { Urinary albumin } \\
\text { excretion rate }(\mathrm{mg} / 24 \mathrm{~h})^{\mathrm{b}}\end{array}$ & $8(0-33)$ & $567(10-8188)$ & - \\
\hline Serum creatinine $(\mu \mathrm{mol} / \mathrm{l})^{\mathrm{b}}$ & $81(55-121)$ & $109(53-558)$ & $<0.001$ \\
\hline Total cholesterol (mmol/l) & $5.0 \pm 0.7$ & $5.6 \pm 1.2$ & $<0.001$ \\
\hline HDL cholesterol (mmol/l) & $1.7 \pm 0.5$ & $1.5 \pm 0.5$ & 0.01 \\
\hline Triglyceride $(\mathrm{mmol} / \mathrm{l})^{\mathrm{b}}$ & $0.8(0.4-2.1)$ & $1.2(0.4-8.8)$ & $<0.001$ \\
\hline Haemoglobin (mmol/l) & $8.8 \pm 0.8$ & $8.2 \pm 0.9$ & $<0.001$ \\
\hline Insulin dosage (IU/day) & $42 \pm 13$ & $43 \pm 12$ & NS \\
\hline Retinopathy & & & $<0.001$ \\
\hline Nihil & 51 & 0 & \\
\hline Simplex & 68 & 24 & \\
\hline Proliferative & 21 & 81 & \\
\hline
\end{tabular}

Table 2. Left ventricular structure and function in Type I diabetic patients with and without diabetic nephropathy

\begin{tabular}{lccl}
\hline & $\begin{array}{l}\text { Normo- } \\
\text { albuminuria } \\
(n=140)\end{array}$ & $\begin{array}{l}\text { Diabetic } \\
\text { nephropathy } \\
(n=105)\end{array}$ & $p$-value \\
\hline LVDD $(\mathrm{mm})$ & $49.7 \pm 4.7$ & $48.7 \pm 4.6$ & 0.07 \\
LVDS $(\mathrm{mm})$ & $29.6 \pm 4.0$ & $28.4 \pm 4.4$ & 0.03 \\
STD $(\mathrm{mm})$ & $8.6 \pm 1.3$ & $9.3 \pm 1.6$ & $<0.001$ \\
PWTD $(\mathrm{mm})$ & $8.6 \pm 1.2$ & $9.2 \pm 1.3$ & $<0.001$ \\
LVM $(\mathrm{g})$ & $173.0 \pm 49.5$ & $185.7 \pm 49.6$ & 0.05 \\
LVMI $\left(\mathrm{g} / \mathrm{m}^{2}\right)$ & $91.4 \pm 21.9$ & $100.6 \pm 23.9$ & 0.002 \\
FS $(\%)$ & $41 \pm 5$ & $42 \pm 6$ & 0.12 \\
PE $(\mathrm{cm} / \mathrm{s})$ & $88 \pm 14$ & $87 \pm 18$ & $\mathrm{NS}$ \\
PA $(\mathrm{cm} / \mathrm{s})$ & $69 \pm 14$ & $77 \pm 15$ & $<0.001$ \\
E/A ratio & $1.34 \pm 0.32$ & $1.17 \pm 0.29$ & $<0.001$ \\
IVRT $(\mathrm{ms})$ & $74.6 \pm 14.5$ & $81.7 \pm 16.5$ & 0.002 \\
\hline
\end{tabular}

means \pm SD

treatment. Nephropathic patients had a slightly increased systolic blood pressure, and in addition raised serum creatinine and $\mathrm{HbA}_{1 \mathrm{c}}$, while haemoglobin concentrations were lower compared with patients with normoalbuminuria. The frequency of antihypertensive treatment was higher in these patients. Treatment with an angiotensin converting enzyme inhibitor was predominant $(62 \%)$ often in combination with calcium channel blockers $(23 \%)$ or beta-blockers $(14 \%)$, prescribed for patients with nephropathy while only 5 normoalbuminuric patients were treated with the latter antihypertensive drugs. Finally the resting heart rate was increased and beat-to-beat variation during deep breathing decreased in the nephropathic vs the normoalbuminuric group, $80 \pm$ 10 vs $75 \pm 15$ beats/min and $9 \pm 7$ vs $15 \pm 9$ beats/min, $p<0.01$ and $p<0.001$, respectively.

In all patients the left ventricle contracted symmetrically and showed no sign of focal hypokinetic segments.

LVMI was higher in patients with diabetic nephropathy $100.6 \pm 23.9 \mathrm{~g} / \mathrm{m}^{2}$ compared with normoalbuminuric patients $91.4 \pm 21.9 \mathrm{~g} / \mathrm{m}^{2}, p=0.002$. In addition, the prevalence of $\mathrm{LVH}$ was considerably increased in patients with nephropathy 23 (14-31)\% vs $9(5-14) \%$ in normoalbuminuric Type I patients, $p<0.005$. Both increased STD and PWTD contribute to the increased LVM seen in nephropathic patients (Table 2.). Exclusion of patients with diabetic nephropathy who due to ongoing antihypertensive medication had a urinary albumin excretion rate below $300 \mathrm{mg} / 24 \mathrm{~h}$ did not alter the results: LVMI was $105.0 \pm 23.3 \mathrm{~g} / \mathrm{m}^{2}$ in the remaining nephropathic patients, $p<0.0001$ compared with the normoalbuminuric group.

When men and women were analysed separately, patients with nephropathy had a higher LVMI compared with patients of the same sex in the normoalbuminuric group, $106.7 \pm 21.1$ vs $99.2 \pm 20.2 \mathrm{~g} / \mathrm{m}^{2}$ for men, $p<0.05$ and $92.2 \pm 25.3$ vs $81.4 \pm 19.8 \mathrm{~g} / \mathrm{m}^{2}$ for women, $p<0.05$. In patients with nephropathy the LVMI was similar in patients with serum creatinine concentrations above [165(111-558) $\mu \mathrm{mol} / \mathrm{l}]$ vs below [87(53-109) $\mu \mathrm{mol} / 1]$, the median value being $102 \pm 27$ $\mathrm{g} / \mathrm{m}^{2}$ vs $99 \pm 20 \mathrm{~g} / \mathrm{m}^{2}$, respectively (NS). Furthermore, there was hardly a difference in the number of nephropathic patients with $\mathrm{LVH}$ and either a normal or increased serum creatinine concentration ( $>109 \mu \mathrm{mol} /$ 1), 9 vs 15 had $\mathrm{LVH}$ respectively, $p=0.25$. Patients with nephropathy and LVH had a higher systolic blood pressure $151 \pm 20$ vs $137 \pm 14 \mathrm{mmHg}$ and serum creatinine concentration 132(64-558) vs 105(53-349) $\mu \mathrm{mol} / 1 \quad(p<0.01)$ compared with nephropathic patients with normal left ventricular mass, while age, duration of diabetes, metabolic control and urinary albumin excretion rate were similar in patients with and without LVH.

Sex, age, blood pressure, $\log _{10}$ (urinary albumin excretion rate), and $\log _{10}$ (creatinine) were associated with LVMI in univariate regression analyses, while duration of diabetes, BMI, $\mathrm{HbA}_{1 \mathrm{c}}$, lipids, haemoglobin, and insulin dosage were not (data not shown). A multiple linear regression analysis with backwards selection showed that only systolic blood pressure and male sex were independent risk factors for LVMI in patients with diabetic nephropathy $\left(\mathrm{r}^{2}=0.34\right)$. 
Patients with diabetic nephropathy had a noticeably reduced diastolic function, assessed by E/A ratio and IVRT compared with patients with normoalbuminuria, while systolic function, assessed by fractional shortening, was normal and about the same in the two groups (Table 2). A negative, albeit weak, correlation between E/A ratio and LVMI was found overall $(r=-0.13, p=0.04)$, no relation was found among patients with nephropathy. The E/A ratio was lower $(1.10 \pm 0.25)$ in nephropathic patients with a serum creatinine concentration above the median (109 $\mu \mathrm{mol} / \mathrm{l})$ compared with patients with nephropathy and a serum creatinine below the median value $(1.23 \pm 0.31), p=0.03$. In the nephropathic group an inverse correlation between E/A ratio and $\log _{10}$ (creatinine) was found, $r=-0.29, p<0.005$. In nephropathic patients with impaired beat to beat variation ( $<15$ beats $/ \mathrm{min}$ ) the E/A ratio was reduced $(1.14 \pm$ $0.26)$ compared with patients with preserved autonomic function $(1.36 \pm 0.38), p=0.004$, whereas IVRT did not differ significantly $(p=0.17)$, in patients with and without autonomic dysfunction, $82.5 \pm 16.4$ vs $75.5 \pm 15.8 \mathrm{~ms}$, respectively.

\section{Discussion}

Our cross-sectional cohort study showed an increased LVMI and a higher prevalence of LVH in Type I patients with diabetic nephropathy compared with patients with normoalbuminuria and although the mean value of LVMI was still within the normal range, its increase was particularly due to a thicker septal and posterior wall. The increased LVMI and the prevalence of LVH occurred early in the course of diabetic kidney disease. Multiple linear regression analysis showed that increased systolic blood pressure and male sex were independent predictors of LVMI in the nephropathic group. Also, patients with nephropathy had impaired diastolic function while systolic function was normal and about the same in the two groups.

Structural and functional abnormalities were described in 17 Type I diabetic patients with diabetic nephropathy $[11,12]$. An increased septal and posterior wall thickness was noted in addition to an increased LVM. Another study found isolated intraventricular septal hypertrophy in persistently albuminuric Type I patients $(n=12)$ with normal serum creatinine, while both septal wall thickness and LVM were increased in patients $(n=8)$ with diabetic nephropathy and impaired renal function [13]. Concentric left ventricular hypertrophy was said to be present in $50 \%$ of 116 diabetic patients entering dialysis [14]. On the contrary, no correlation between left ventricular muscle mass index and a diabetic complication index was detected, scoring nephropathy, retinopathy and cardiac autonomic neuropathy as one variable
[15]. In this study of 105 Type I diabetic patients with nephropathy that had not yet reached end stage renal failure, $23 \%$ of the patients had left ventricular hypertrophy. Our data suggest that hypertrophy of the left ventricle occurs early in the course of diabetic nephropathy, since LVMI and the prevalence of LVH is equally increased in the group of nephropathic patients with a serum creatinine below or above the median value $(109 \mu \mathrm{mol} / \mathrm{l})$. Whether this early increase in LVMI will eventually progress to established LVH remains to be clarified.

This study confirms and extends previous studies showing a positive correlation between LVM and blood pressure in Type I diabetic patients who are not taking blood pressure lowering drugs [13] or treated with diuretics [11]. This relation exists although the majority of nephropathic patients received aggressive antihypertensive treatment. Since hypertensive patients with renal dysfunction due to diabetic nephropathy frequently are non-dippers and therefore lack the normal decline in blood pressure during night time, we may well have overlooked a nocturnal blood pressure effect.

The observation, that left ventricular diastolic dimension was not increased implies that volume overload does not have a major role in the pathogenesis of $\mathrm{LVH}$ in diabetic nephropathy. $\mathrm{LVH}$ is known to be influenced by several nonhaemodynamic factors that may also increase coronary damage, these include obesity and increasing age [16], increased blood viscosity [17], high salt intake [18], and insulin resistance [19]. In our study, the two groups of Type I diabetic patients were on an ordinary diabetic diet without salt restriction and on similar dosages of insulin. We did not measure blood viscosity or insulin sensitivity. Sodium-lithium erythrocyte countertransport is enhanced in diabetic nephropathy $[20,21]$ and this abnormality has been suggested to be associated with LVH [22].

Patients with diabetic nephropathy had a poorer metabolic control compared with patients with normoalbuminuria which is in agreement with previous studies [23]. Given this reflects a persistently higher glucose concentration over several years this metabolic abnormality might contribute to the development of increased LVMI in Type I patients with nephropathy; however, no correlation between actual measured $\mathrm{HbA}_{1 \mathrm{c}}$ and LVMI was found.

Originally diastolic dysfunction was said to occur early in the course of diabetic nephropathy and frequently in the absence of left ventricular systolic impairment [24] which was later confirmed [15, 25]. The findings of a reduced E/A ratio and an increased PA filling velocity together with a prolonged IVRT is in accordance with observations of abnormal relaxation seen in patients with another disease of the myocardium, early cardiac amyloidosis [26] and in diabetic patients with early persistent proteinuria and 
normal kidney function [24]. In addition, our data suggest impaired or abolished autonomic function as a potential contributor to impaired diastolic function. It is unlikely that our findings of impaired diastolic function among patients with nephropathy can be ascribed to ongoing antihypertensive therapy, since the use of medications with potential beneficial effect on diastolic function is much more common in the nephropathic group.

Left ventricular systolic function is not impaired until late in the progression of overt diabetic nephropathy $[12,14,24]$ and thus was not found among our study subjects with well preserved kidney function.

In a prospectively followed cohort of 116 diabetic patients on dialysis increased LVMI was frequent and found to be associated with a higher mortality rate [14]. Therefore, our findings of increased LVMI and impaired diastolic function rather early in the course of diabetic nephropathy in Type I diabetic patients might contribute to the excess cardiac mortality characteristically found in this group of patients.

\section{References}

1. Borch-Johnsen K, Kreiner S (1987) Proteinuria: value as predictor of cardiovascular mortality in insulin dependent diabetes mellitus. BMJ 294: 1651-1654

2. Frolich E, Apstein C, Chobanian AV et al. (1992) The heart in hypertension. N Engl J Med 327: 998-1008

3. Tarnow L, Cambien F, Rossing P et al. (1995) Lack of relationship between an insertion/deletion polymorphism in the angiotensin-I-converting enzyme gene and diabetic nephropathy and proliferative retinopathy in IDDM patients. Diabetes 44: 489-494

4. Tarnow L, Cambien F, Rossing P et al. (1995) Insertion/deletion polymorphism in the angiotensin-I-converting enzyme gene is associated with coronary heart disease in IDDM patients with diabetic nephropathy. Diabetologia 38: 798-803

5. Parving $\mathrm{H}-\mathrm{H}$, Andersen AR, Smidt UM, Svendsen PA (1983) Early aggressive antihypertensive treatment reduces rate of decline in kidney function in diabetic nephropathy. Lancet I:1175-1179

6. Schiller NB, Shah PM, Crawford M et al. (1989) Recommendations for quantitation of the left ventricle by two-dimensional echocardiography. Journal of the American Society of Echocardiography 2: 358-367

7. Devereux RB, Reichek N (1977) Echocardiographic determination of left ventricular mass in man: anatomic validation of the method. Circulation 55: 613-618

8. Savage DD, Garrison R J, Kannel WB et al. (1987) The spectrum of left ventricular hypertrophy in a general population sample: The Framingham study. Circulation 75 [Suppl 1]: 1-26

9. Hilsted J, Jensen SB (1979) A simple test for autonomic neuropathy in juvenile diabetics. Acta Med Scand 205: 385-387
10. Feldt-Rasmussen B, Dinesen B, Deckert M (1985) Enzyme immunoassay: an improved determination of urinary albumin in diabetics with incipient nephropathy. Scand J Clin Lab Invest 45: 539-544

11. Thuesen L, Christiansen JS, Mogensen CE, Henningsen P (1988) Echocardiographic-determined left ventricular wall characteristics in insulin-dependent diabetic patients. Acta Med Scand 224: 343-348

12. Thuesen L, Christiansen, Mogensen CE, Henningsen $P$ (1988) Cardiac hyperfunction in insulin-dependent diabetic patients developing microvascular complications. Diabetes 37: 851-856

13. Sampson MJ, Chambers JB, Drury PL (1990) Intraventricular septal hypertrophy in type 1 diabetic patients with microalbuminuria or early proteinuria. Diabet Med 7: 126-131

14. Foley RN, Culleton BF, Parfrey PS et al. (1997) Cardiac disease in diabetic end-stage renal disease. Diabetologia 40: $1307-1312$

15. Raev DC (1994) Which left ventricular function is impaired earlier in the evolution of diabetic cardiomyopathy? Diabetes Care 17: 633-639

16. Messerli FH, Sundgaard-Riise K, Ventura HO, Dunn FG, Oigman W, Frolich ED (1984) Clinical and hemodynamic determinants of left ventricular dimensions. Arch Intern Med 144: 477-481

17. Devereux RB, Drayer JIM, Chien S (1984) Whole blood viscosity as a determinant of cardiac hypertrophy in systemic hypertension. Am J Cardiol 54: 592-595

18. Schmieder RE, Messerli FH, Garavaglia GE, Nunez BD (1988) Dietary salt intake. A determinant of cardiac involvement in essential hypertension. Circulation 78: 951-956

19. Lind L, Andersson PE, Andrén B, Hänni A, Lithell HO (1995) Left ventricular hypertrophy in hypertension is associated with the insulin resistance metabolic syndrome. J Hypertens 13: 433-438

20. Krolewski AS, Canessa H, Warram JH et al. (1988) Predisposition to hypertension and susceptibility to renal disease in insulin-dependent diabetes mellitus. N Engl J Med 318: 140-145

21. Mangili R, Bending JJ, Scott GS, Lai LK, Gupta A, Viberti GC (1988) Increased sodium-lithium counter transport activity in red cells of patients with insulin dependent diabetes and nephropathy. N Engl J Med 318: 146-150

22. Sampson MJ, Denver E, Foyle WJ, Dawson D, Pinkney J, Yudkin JS (1995) Association between left ventricular hypertrophy and erythrocyte sodium-lithium exchange in normotensive subjects with and without NIDDM. Diabetologia 38: 454-460

23. Parving H-H, Østerby R, Anderson PW, Hsueh WA (1996) Diabetic nephropathy. In: Brenner BM (ed) The Kidney, 5th edn. Saunders, Philadelphia, pp 1864-1892

24. Sampson MJ, Chambers JB, Sprigings DC, Drury PL (1990) Abnormal diastolic function in patients with type 1 diabetes and early nephropathy. Br Heart J 64: 266-271

25. Watschinger B, Brunner C, Wagner A et al. (1993) Left ventricular diastolic impairment in type 1 diabetic patients with microalbuminuria. Nephron 63: 145-151

26. Klein AL, Cohen GI (1992) Doppler echocardiographic assessment of constrictive pericarditis, cardiac amyloidosis, and cardiac tamponade. Cleveland Clinic Journal of Medicine 59: 278-290 